\title{
Polymeric surfaces with biocidal action: challenges imposed by the SARS-CoV-2, technologies employed, and future perspectives
}

\author{
Karine Cappuccio de Castro $^{1}$ (D) . Josiel Martins Costa ${ }^{1}$ (D)
}

Received: 8 April 2020 / Accepted: 20 April 2021 / Published online: 31 May 2021

(c) The Polymer Society, Taipei 2021

\begin{abstract}
The COVID-19 pandemic has demonstrated that hygiene habits reduce the spread of the SARS-CoV-2 virus on contaminated surfaces. In this context, compounds with biocidal properties can act as surface coatings, especially in hospital environments, a source of pathogenic microorganisms. Therefore, the purpose of this review was to report an overview of recent studies with biocidal agents, focusing on polymeric surface modification. Methods such as direct incorporation, direct deposition, and chemical deposition of the microbial agent on the polymeric surface and surface modification without a microbial agent were discussed. Despite several studies in the literature, antimicrobial materials still face challenges such as commercialization, material stability in post-processing, and guarantee of long cycles. Moreover, effectiveness, toxicity, and final cost must be balanced. We also discussed the concept of antiviral activity and the action mode of the materials. Inorganic, organic materials, nanocomposites, and biopolymers have been addressed as viral inhibitors of several diseases. Lastly, we explored the functional validation of polymeric surface through characterization techniques.
\end{abstract}

Keywords Antiviral activity $\cdot$ Biocompatibility $\cdot$ COVID-19 $\cdot$ Nanoparticles $\cdot$ Surface modification

\section{Introduction}

The latest world events related to the pandemic caused by SARS-CoV-2 have shown that the way we live and hygiene habits are directly related to the spread of diseases caused by microorganisms such as bacteria, viruses, and fungi. The spread of diseases can occur simply by contact with contaminated surfaces, giving rise to major social issues worldwide, as observed in the last year. The safe extermination of the microorganisms is important for human health. Recent research indicates that researchers' interest is largely focused on using the multitude compounds' biocidal properties, for covering surfaces, especially in environments hospitals, as these sites are constant sources of pathogens [1].

The surfaces act as reservoirs of microbes, which can lead to the spread of infection when touched. In the hospital environment, pathogens usually propagate in two ways: (1) common objects within the hospital environment that can

Karine Cappuccio de Castro

cappuccio.karine@gmail.com

1 School of Chemical Engineering, University of Campinas, Campinas, SP, Brazil become contaminated; (2) handling (with or without gloves) that can contaminate the hands after touching contaminated surfaces [1].

Researches aimed at studying the new coronavirus pandemic (COVID-19) reported that SARS-CoV-2 is transmitted mainly from infected people through contact routes and cough droplets or sneezes, and transmission through the airways. The experimental results indicated that when dispersed, the drops settle on smooth surfaces, survive up to 4 days on glasses and banknotes, and 7 days on stainless steel and plastics [2, 3].

Thinking about these aspects, the role of material surfaces in the transmission of diseases is evident. It is important to study surface coatings with biocidal action so that these coatings are durable in the long term, present low toxicity to humans, and are ecologically sustainable.

In general, antimicrobial agents are divided into four broad categories: (1) oxidants, containing chlorine and peroxides; (2) electrophilic agents, such as the metals Ag, $\mathrm{Cu}$, and $\mathrm{Hg}$; (3) organic biocides, such as formaldehyde and isothiazolinone; (4) cationic active biocides, such as chlorhexidine and quaternary ammonium compounds. However, the toxicity of these molecules can harm the environment. The difficulty in controlling the diffusion rate decreases its 
protection, resulting in low durability [4, 5]. Therefore, it is interesting to synthesize polymers with antimicrobial function or serve as a matrix to transport these biocidal agents.

Generally, polymeric antimicrobial agents have the following advantages: (1) in general, they do not volatilize and are chemically stable; (2) the intended application temperature is the same as the storage; (3) its insolubility in water allows application in water disinfection processes; (4) the biomaterials do not permeate through the skin; (5) for the most part, their syntheses are easily controlled and economically viable $[4,6-8]$.

In this context, this review focuses on the main biocidal agents and how they can be used for surface coating, focusing mainly on polymer modification, coatings using polymeric matrices as biocidal agents or as carriers of other biocidal agents (for example, metals/oxides, ceramic, others). The synergistic combination of the mechanisms to provide various functional antimicrobials to combat pathogens was addressed. This review also provides an overview of the main characterization techniques used to characterize biofunctionalized surfaces to validate the proposed methodologies and develop accurate methods for production reproduced on a large scale.

\section{Antiviral activity}

The virus replication cycle generally follows three steps: (1) initial entry and penetration into the host cell; (2) replication and protein synthesis; (3) the sprouting of new virions [9]. Extracellular intervention promotes the inhibitory action of the virus before entering the cell. The interactions of virus connections with the host cell at viral entry are specific and target viral entry inhibition [10]. Inactivating the virus before entry is the most direct antiviral approach, proven by indirect mechanisms. Nanoparticles of silver (AgNPs) and gold were synthesized by algae of the species Oscillatoria sp. and S. platensis [11]. Both nanoparticles inhibited the replication of Herpes Simplex virus (HSV-1) infection to Vero cells in a dose-dependent manner, which reduced $90 \%$ of the cytopathic effect of HSV-1 by 31.25 $\mu \mathrm{L}$. For the authors, the biological preparation of metallic nanoparticles using blue-green algae is an efficient way of producing antiviral agents. AgNPs are known for interfering in virus particles' binding to the host cell, preventing their entry. However, the exact antiviral action has not yet been fully understood [12]. The interaction of AgNPs with cells is complex, and studies need to elucidate the cytotoxic potential of nanoparticles.

Several materials have antiviral action blocking the entry of the virus. The antiviral activity before the entry of the virus became speculative by the researchers. Chitosan curcumin nanocomposites ( $\mathrm{CuCs}$ ) have been developed as a potential antiviral agent for hepatitis C (HCV-4a) in Huh7 human hepatoma cells [13]. CsNPs had no cytotoxic effect on cell lines. The expression of apoptotic genes indicated the mechanism of the caspase-dependent pathway. Viral entry and replication were inhibited by the action of CsNPs and $\mathrm{CuCs}$ nanocomposites, also confirmed by the expression of the HCV nuclear protein. Du et al. [14] developed graphene oxide nanocomposites modified with silver nanoparticles (GO-AgNPs) by interfacial electrostatic force. Nanocomposites suppressed the entry of the porcine respiratory and reproductive syndrome virus into the host cell, suppressing virus replication.

Antiviral agents also act in interfering with the virus cell's binding process. Rogers et al. [15] evaluated the ability of AgNPs to inhibit monkeypox virus infection through in vitro assays. AgNPs with and without polysaccharide coating $(10-80 \mathrm{~nm})$ blocked the penetration and binding of the virus-cell, indicating its potential use as antiviral therapy. Although antiviral materials' mechanisms are described with different terminologies in the literature, they boil down to competition or inhibition of the binding process between the virus and the host cell [16].

In addition to metallic nanoparticles, polymeric nanoparticles also have antiviral action. In veterinary medicine, the administration of nanoencapsulated interferon polymers is an alternative to low-effective vaccines against infectious diseases [17]. The cellular immune response and antiviral activity block the multiplication of the pathogen. Faced with the COVID-19 pandemic, biocompatible polymers tested in vitro and in vivo may be a strategy for inhibiting angiotensin-converting enzyme 2 (ACE-2) receptors [18]. These materials bind to ACE- 2 receptors and can block the virus from entering the host cell. The antiviral action of these materials prevents ocular contamination of the COVID-19 virus in healthcare professionals.

\section{Materials with antiviral activity}

\section{Inorganic materials}

Inorganic materials based on metals, carbon, and silica nanoparticles have been of great interest in biomedical research due to their superior biocompatibility, unique structures, and physical and chemical characteristics. Noble gold and silver nanoparticles have versatility in surface functionalization and the ability to cleave disulfide bonds. Efficient interaction with capsids and toxicity to the organism depends on the morphology and NPs size. The high surface area provides many adsorption and reaction sites for further modification, allowing NPs atoms to combine with other atoms by chemical bonds. The superficial chemistry control allows to stabilize 
NPs in the biological environment, add targeting agents, and increase the circulation time in the body [19].

Although AgNPs have a wide biological application, their potential for pollution and self-aggregation limits their activity. Besides, naked AgNPs can harm human health [20]. In this context, modified and stable surfaces that protect the molecular layers have been developed. The possible mechanisms of action of AgNPs with modified surfaces are broad. They include the inhibition of neuraminidase and hemagglutinin activity [21], prevention and fixation of virus penetration [22], and inhibition of ROS accumulation and activation of AKT and p53 [23].

AuNPs have less toxicity compared to AgNPs, having greater application in vivo. They interact with hemagglutinin, where the $\mathrm{Au}$ atom oxidizes the disulfide bond, resulting in the glycoprotein's inactivation. The targeting of hemagglutinin emerged as an alternative to real therapy, such as neuraminidase, being indicated for viruses with fast mutation speed, which is resistant and deadly [24].

Carbon-based antiviral nanomaterials have attracted attention due to their high performance, versatility, and diversity. Carbon nanotubes (CNTs) [25], fullerenes [26], graphene oxide (GO) [27], or carbon dots [28] are extensively studied. Mazzaglia et al. [29] used multi-walled carbon nanotubes of $\beta$-cyclodextrin (MWCNT-CD) modified with branched polyethyleneimine (PEI) and doped with rhodamine (Rhod) for drug delivery. TEM images in Fig. 1 show a multi-walled tube structure with diameters from 5 to $10 \mathrm{~nm}$, with a number of layers close to eight. Amorphous regions lined the outer edges of the nanotube, as shown in Fig. 1a. CDs were grafted into the amorphous shell of the MWCNTs surfaces. Figures $1 \mathrm{~b}, \mathrm{c}$ and d show an amorphous interphase $\mathrm{c}$ region with nanotubes dispersed in the PEI network. The MWCNT-CD-PEI-Rhod system allowed the trapping and delivery of Cidofovir and did not indicate significant cytotoxicity. MWCNT-CD-PEI-Rhod loaded with Cidofovir and/or DNA plasmid encoding enhanced green fluorescence protein crossed the cell membrane co-located in the lysosomal compartment by a clathrin-dependent pathway.
Bulky fullerene acts by blocking HIV virus-encoded enzymes, fitting into the active protease sites. A diaphanous diphenyl fulleroid derivative was developed to inactivate the HIV enzyme [30]. Yasuno et al. [31] synthesized fullerene derivatives (pyridinium trans-3a and 4a-5b, piperidinium 9 and proline 10a-12) according to the structure exhibited in Fig. 2. Compounds 5a, 10e, 10f, 10i, 11a-d, and 12 inhibited both HIV reverse transcriptase and protease. The alkyl chain connection of hydroxymethylcarbonyl fractions with fullerene of the proline type led to improved inhibition of HIV protease.

GO has oxygenated reactive groups on its surface. The adsorption and destruction of viruses can occur through electrostatic forces and redox reactions on the material surface [32]. The capsid protein composed of arginine or the virus's positive charges allows these interactions [33]. GO inhibited herpes simplex virus type 1 infection [34]. Both derivatives ( $\mathrm{GO}$ and reduced $\mathrm{GO} \mathrm{SO}_{3}$ ) exhibited antiviral activity at low concentrations $\left(\mathrm{ng} \mathrm{mL}^{-1}\right)$. Cytotoxicity tests demonstrated the non-toxic nature of the material.

Carbon quantum dots are non-toxic in animals and have an average diameter of less than $10 \mathrm{~nm}$ [35]. Its optical property allows in vivo tracking. The antiviral activity of carbon quantum dots was used to treat the coronavirus HCoV-229E [36]. The nanostructures obtained from the hydrothermal carbonization of ethylenediamine/citric acid indicated a concentration-dependent virus inactivation (50\% effective inhibition $-52 \pm 8 \mu \mathrm{g} \mathrm{mL}^{-1}$ ). To the authors, the mechanism of action occurred through the functional group interaction of the nanostructure with the $\mathrm{HCoV}-229 \mathrm{E}$ input receptors.

\section{Organic materials}

Organic nanomaterials include polymeric structures, lipidbased structures, dendrimers, and micelles. Its versatility in size and morphology provides biocompatibility and biodegradability, allowing virucidal action to treat viruses effectively. The encapsulation of drugs in a polymeric matrix or their absorption on the surface increases bioavailability, circulation time in the human organism and decreases side
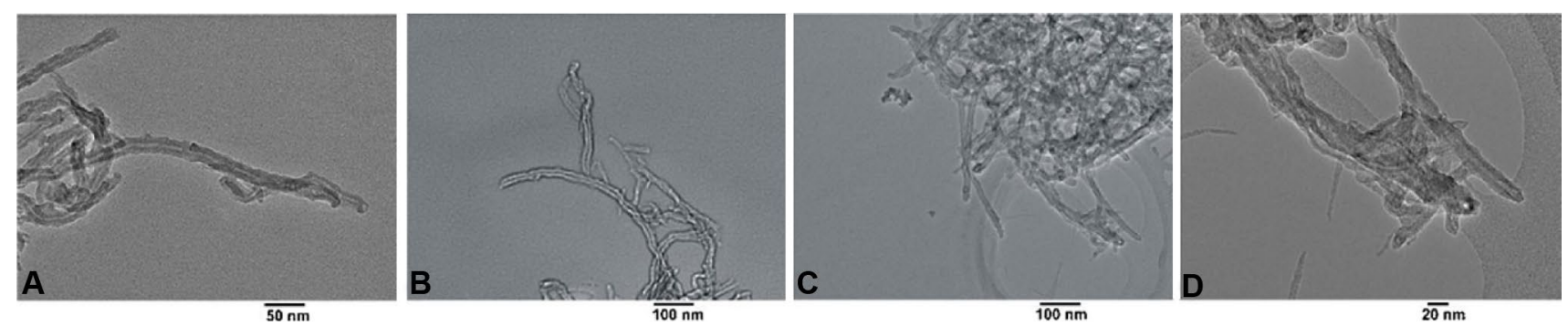

Fig. 1 TEM images of functionalized MWCNTs: a MWCNT-CD; b MWCNT-CD-PEI; $\mathbf{c}$ and d MWCNT-CD-PEI-Rhod. Reproduced with permission from Ref. [29]. Copyright 2018, Elsevier 


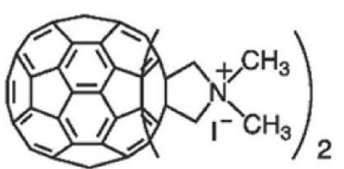

1

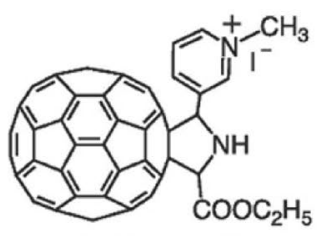

cis-3a, trans-3a

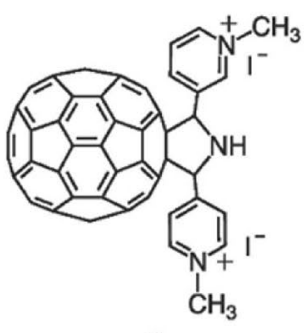

$6 \mathrm{a}$

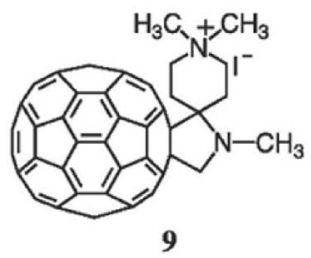

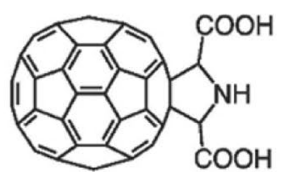

2a

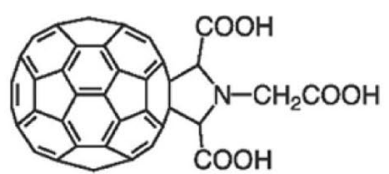

2b

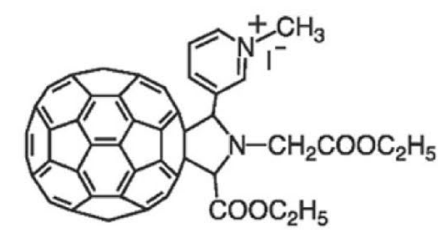

3b

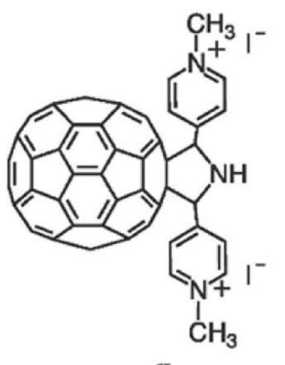

6b

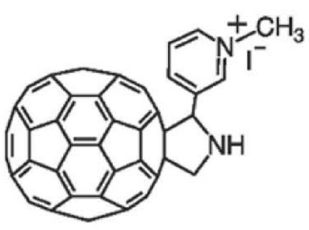

$3 c$

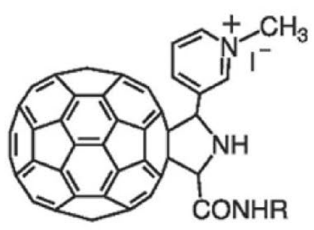

4a $\mathrm{R}=\mathrm{CH}_{3}$

4b $\mathrm{R}=\mathrm{C}_{2} \mathrm{H}_{5}$

5a $\quad \mathrm{R}=\mathrm{OCH}_{3}$

5b $\mathrm{R}=\mathrm{OC}_{2} \mathrm{H}_{5}$

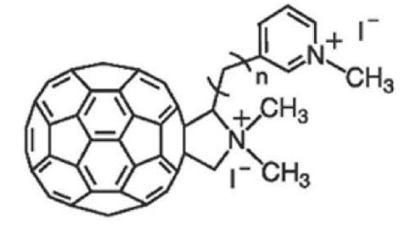

7a $\mathrm{n}=1$

$\begin{array}{ll}7 b & n=4 \\ 7 c & n=6\end{array}$

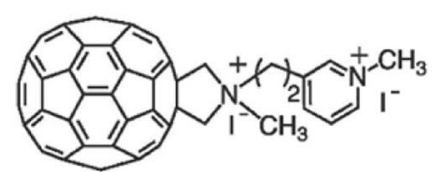

8

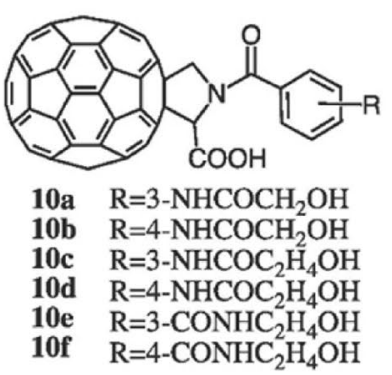

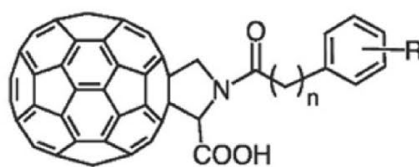

11a $\mathrm{R}=3-\mathrm{NHCOCH}_{2} \mathrm{OH}, \mathrm{n}=1$

11b $\mathrm{R}=4-\mathrm{NHCOCH}_{2} \mathrm{OH}, \mathrm{n}=1$

11c $\mathrm{R}=3-\mathrm{NHCOCH}_{2} \mathrm{OH}, \mathrm{n}=2$

11d $\mathrm{R}=4-\mathrm{NHCOCH}_{2} \mathrm{OH}, \mathrm{n}=2$

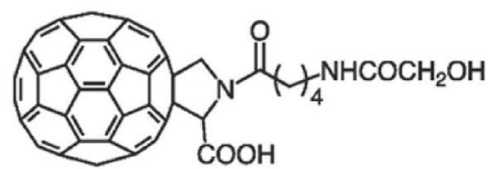

12

Fig. 2 Structure of fullerene derivates. Reproduced with permission from Ref. [31]. Copyright 2020, Elsevier

effects. Lin et al. [37] developed hollow capsid-like polymeric NPs to deliver viral subunit antigens and stimulator of interferon gene agonists. Nanoencapsulation showed a release profile responsive to $\mathrm{pH}$ and local immune activation. The poly(lactic-co-glycolic acid) NPs vaccine against the Middle East respiratory syndrome coronavirus presented sustained efficacy by neutralizing antibodies and $\mathrm{T}$ cell responses in immunized mice.

Organotin polymers can be used as antiviral agents [38]. Organotin has a long retention time in the bloodstream as a better effect compared to acyclovir, attributed to (1) high molecular weight, leading to slow filtration in the kidney; (2) condensed structure, increasing the local concentration and facilitating the connection between the polymer and the target; (3) Little resistance of cells to polymers, protecting host cells against virus invasion; (4)
Size and structure, which inhibits the virus from attacking the host cell [39].

Dendrimers are versatile and biocompatible polymers, composed of hyperbranched molecules with various functional groups on their surface. Features such as versatility, water solubility, and internal cavities make them useful for formulation and nanoconstruction in drug delivery [40]. Janus amphiphilic dendrimers formed micelles suitable for encapsulating camptothecin in therapy against the hepatitis $\mathrm{C}$ virus. The micelles reduced the toxicity, increased the solubility, and maintained the drug's stability at physiological $\mathrm{pH}$. They increased the antiviral activity once the lactone ring present in the camptothecin molecule is hydrolyzed to physiological $\mathrm{pH}$. The camptothecin-loaded dendrimer inhibited replication of viruses $\mathrm{HCV}$ and demonstrated low toxicity using low drug concentration. 


\section{Nanocomposites}

Nanocomposites are heterogeneous materials with at least one of the components having one of the three dimensions on a nanometric scale [41]. Cytotoxic or genotoxic damage caused by AgNPs makes adding other material in the composition an important topic. Park et al. [42] evaluated a hybrid silica nanocomposite decorated with $\operatorname{AgNP}(30 \mathrm{~nm})$ to inactivate the virus that causes seasonal influenza. The particles of $\mathrm{Ag}-\mathrm{SiO}_{2}$ inhibited the virus in a dose-dependent manner. After $1 \mathrm{~h}$ of exposure to the nanocomposite, $80 \%$ of damage to hemagglutinin and $20 \%$ of neuraminidase activity still occurred. Besides, viral infection in canine kidney cells has been reduced. For the authors, $\mathrm{Ag}-\mathrm{SiO}_{2}$ caused unspecific damage to several components of the virus.

Graphene oxide has also been found in the composition of nanocomposites [43]. The authors compare the viral inhibition capacity of graphene oxide sheets and graphene oxide sheets with silver particles (GO-Ag) against feline coronavirus (FCoV). The nanocomposite of GO-Ag inhibited 25\% of FCoV infection, while graphene sheets inhibited $16 \%$. The proposed antiviral activity mechanism was: (1) Binding between opposite charges; (2) Association between lipid tails and aromatic planes of GO; (3) Disruption of the lipid membrane by the GO; (4) Binding between $\mathrm{Ag}$ and $-\mathrm{SH}$ groups of viral proteins.

A strategy for delivering nucleic acid fragments to cells has been suggested using $\mathrm{TiO}_{2}$ nanocomposites [44]. Deoxyribozime (Dz) molecules were immobilized on $\mathrm{TiO}_{2}$ nanoparticles containing polylysine (PL), forming the $\mathrm{TiO}_{2}$-PL-Dz composite. The nanocomposite penetrated the eukaryotic cells and allowed the efficient delivery of Dz, reaching the RNA target within the cells. The drug based on nucleic acid demonstrated high antiviral activity inhibiting the replication of influenza A H5N1 virus.

\section{Biopolymers}

\section{Saccharides}

Saccharides, in general, have attractive properties such as low toxicity, antiviral activity, and biocompatibility. Recent findings are highlighted in this review, according to the most relevant references. Chitosan is a natural polycationic biopolymer composed of subunits of glucosamine and $\mathrm{N}$-acetyl glucosamine. Its application as a biomaterial is related to biocompatibility and antimicrobial action, and performance in the controlled drug release $[45,46]$. The chitosan structure allows protonation in the acidic environment of free amine groups, resulting in the ionic bonding of the drug molecules' reactive groups. Hydroxy groups can easily bond to other molecules by hydrogen. The strategy for the formation of new compounds by these bonds is named encapsulation. It makes cationic biopolymers effective agents of viral drug delivery reducing the diffusion rate and promoting sustained release in the target sites [47, 48].

Antiviral drugs are a class of molecules used to treat viral infections or inhibit viral pathogens. The pharmacokinetics of triazavirin $\left(\mathrm{C}_{5} \mathrm{H}_{4} \mathrm{~N}_{6} \mathrm{O}_{3} \mathrm{~S}\right)$ have been improved via liposome encapsulation with modified chitosan [49]. An appropriate combination of liposomes and polysaccharide layer provided colloidal stability is up to 3 months, demonstrating the extensive capability for surface modification. Meanwhile, Donalisio et al. [50] prepared chitosan nanospheres by a modified nanoemulsion mold method. The nanomaterial loaded with acyclovir demonstrated a $30 \%$ release of acyclovir after $6 \mathrm{~h}$. The load capacity of the medication was about $8.5 \%$. The drug accumulation in the pigskin was around $1 \%$ for commercial formulation and $30 \%$ for acyclovir released by nanospheres after $24 \mathrm{~h}$. The nanocarrier indicated no antiproliferative activity and could be absorbed by the cells as characterized by laser scanning confocal microscopy.

Cyclodextrins (CD) are versatile and multifunctional oligosaccharide rings. In treating viral infections, the $\mathrm{CD}$ can act as a controlled release and protect the active principle of the medication in a hostile environment. The cavity present in its structure encapsulates the hydrophobic groups, creating inclusion complexes. The chemical structure and properties of the host are not changed [51].

The COVID-19 virus has been encapsulated using CDs. The antiparasitic drug nitazoxanide has demonstrated antiviral activity in vitro against MERS and SARS-CoV-2 [52]. Chloroquine and hydroxychloroquine have been tested in the treatment of patients infected with SARS-CoV-2 [53]. CDs act as chiral selectors, indicating that the carboxyl or sulfate functional groups in CD derivatives are ideal for resolving chloroquine enantiomers [54]. However, recent studies have indicated the limited effectiveness of both drugs against COVID-19 [55]. In general, the structural complexes of saccharides and their derivatives may favor their antiviral actions in viral infection stages, demonstrating clinical applications.

\section{Peptides}

Peptides are compounds derived from natural sources such as bacteria, plants, and animals or synthesized rationally. They can interact with the virus, blocking the connection, and preventing viral fusion [16]. Besides, they may have biocidal activity, breaking the envelope of the virus. The peptides' specificity plays an essential role in stimulating the immune response that inhibits viral replication [56].

Peptides and peptide-based inhibitors are a viable alternative due to their larger sizes, which allow greater efficiency and specificity concerning small molecule drugs, with 
greater tolerance [57]. In contrast, small molecules have higher production costs on a large scale, requiring timeconsuming strategies for their development. The larger size of the molecule makes the peptides tolerable and specific. However, bioavailability and half-life are reduced. Modifying the molecule can improve activity and stability by shortening the sequences, altering amino acids, or adding fractions that increase affinities for the partner [58].

Peptides were designed to target the ACE-2 receptor or the viral Spike protein [59]. The SARS-CoV-2S protein activation depends on proteolytic cleavage at two sites: (1) Initiated at the polybasic site by the host's furin protease, and (2) Processed by the plasma membrane-related TMPRSS2 protease [60]. The activation of $\mathrm{S}$ proteins occurs by lysosomal cathepsin $\mathrm{L}$ and is independent of the initiation measured by furin. However, the role of lysosomal cathepsin $\mathrm{L}$ in vivo is not entirely understood [61]. Inhibition of these proteases prevents SARS-CoV-2 infection. Therefore, the design of inhibitor peptides is a strategy against the COVID-19 virus [59].

\section{Polymeric surface modification}

The surface modification for the generation of biocidal activities should be carefully analyzed despite not presenting complexity. The addition of a biocidal agent can negatively impact the fundamental properties of stability, mechanical resistance, porosity, density, toxicity, and availability of specific chemical functionalities on its surface $[62,63]$.

Surfaces chemically or topographically modified or with intrinsic properties of contact killing or repellents are of great interest to researchers, especially for application in hospital environments. Antimicrobial surfaces actively disrupt and kill contact cells. Anti-biofouling materials are antifouling materials with repellent properties. Hydrophobic and electrostatic interactions, among other mechanisms, allow the fixation of the bacterial surface. Anti-fouling surfaces act by repelling microbial fixation by hydrophobia, negative charge, or low surface energy [64-67].

Anti-fouling coatings repel or control the microbial biofilm architecture on surfaces, preventing their growth. Meanwhile, antimicrobial coatings act by the bacteriostatic or bactericidal effect. The bacteriostatic action consists of the spherical repulsion mechanism or nanoscale topographies. In contrast, the bactericidal action comprises death by contact or release of compounds or organic metal ions, lethal to the cell $[68,69]$. The microbial activity and its mechanism allow to classifying polymers into passive or active materials $[69,70]$. The passive mechanism is based on electrostatic and hydrophilic/hydrophobic repulsions and the matrix's low surface energy. The active mechanism occurs through the electrostatic and biocidal interactions of the material [69].

An appropriate surface modification approach must be determined according to the materials and their applications. From the processing viewpoint, the choice of method considers three criteria: (1) compatibility with the material type, that is, polymeric, metallic, ceramic, or composite; (2) stability, that is, sensitivity temperature, solubility, mechanical strength, among others; (3) physical structure, such as porosity and size (bulk, thin-film, among others) $[62,71]$.

From the application viewpoint, it is important to consider how this material will be requested, the load that the surface will be subjected, wear, flow, or environmental conditions that affect the new material's surface and dimensions. Compatibility of the material with cells, host tissues, and biomolecules is also essential [62]. The type of biocidal agent, its ability to resist processing and maintain its antimicrobial action under physiological conditions, also affects the modification method's choice.

Antimicrobial agents can be added to polymeric surfaces by physical adsorption, ionic interaction, or hydrogen bonds. However, the leaching of microbial agents into the environment and low efficacy limit the use of these manufacturing methods [72]. Based on this assumption, the surface's effectiveness time is another crucial point to be evaluated in the manufacture of antibacterial surfaces. Materials with prolonged effectiveness minimize the spread of infections.

When the polymer has reactive sites, such as hydroxyl and amino groups, chemical bonds with antimicrobial agents are relatively simple. On the other hand, many polymers used in the main consumer goods are inert. In this case, it is necessary to generate functional groups of surfaces to expose functionalized (active) surfaces. Chemical treatments and high energy irradiation promote oxidation reactions, forming reactive groups. However, this method is not always viable and effective [72].

In this context, there are four different ways to modify a polymer so that it has biocidal activity: (1) Direct incorporation of the antimicrobial agent in the polymeric matrix; (2) Direct deposition of the antimicrobial agent on the polymer surface; (3) Chemical deposition of the antimicrobial agent on the polymer surface; (4) Surface properties modification of the polymer without an antimicrobial agent.

\section{Direct incorporation of the antimicrobial agent in the polymeric matrix}

This method consists of adding an antimicrobial agent directly to the polymeric matrix; the most used agents for this purpose are organic or inorganic compounds. One way to carry out this modification is to add the antimicrobial agent in a polymeric solution that is molded later; however, this procedure does not meet the large-scale production and 
is usually used to prepare films and coatings. On the other hand, conventional techniques such as extrusion, injection molding, and blowing can solve large-scale production. In this case, the biocidal agents are mixed with the polymers to be processed [71]. Although it is not a complex method, the restricted diffusivity of the antimicrobial agent molecules through the polymeric matrix decreases the efficiency of the microbial modification, indicating that the applicability objective is not always fully achieved. [71].

\section{Direct deposition of the antimicrobial agent on the polymer surface}

The direct deposition of the biocidal agent to the surface is the simplest way to obtain materials with a functionalized surface; however, its effectiveness is low due to the active component's rapid reabsorption. In this method, the antimicrobial agent is applied to a polymer-based material's surface just before use [71].

\section{Chemical deposition of the antimicrobial agent on the polymer surface}

It is a method similar to the previous method. However, the polymeric surface is previously activated. Then, the biocidal agent is chemically deposited on the polymer surface. The surface activation allows a more stable bond between the antimicrobial agent and the matrix, ensuring activity for an extended period [71].

\section{Surface properties modification of the polymer without an antimicrobial agent}

This method assumes that changing the surface properties of a material can improve its biocidal properties. The modification can be carried out by several mechanisms, such as wet reactions, reactions with various chemical reagents, application of techniques using high energy (i.e., electromagnetic radiation, use of plasma, and ultrasound). The interaction of a polymer's surface with electromagnetic radiation causes activation of the surface (breaking accessible polymeric bonds), allowing for subsequent chemical modification. Ionized gas (plasma) is another modification alternative, despite presenting low long-term stability [71]. It is worth mentioning that the combination of mechanisms can be interesting and advantageous.

\section{Coating strategies using polymeric matrices}

Antimicrobial layers are materials whose structure has portions with biocidal activity, such as nanoparticles/polymers/ chemically integrated natural bioactive polymers. They work by eliminating or controlling the germination of pathogenic microorganisms, parasites, and infections. With the passage of the microbial film, the addition of pathogens to the surface is inhibited. Hybrid antimicrobial films of $\mathrm{Ag}, \mathrm{Cu}$, and Zn cations demonstrated virucidal impacts in hidden infections, for example, HIV-1, human herpes virus 1, and dengue type 2 and, therefore, have great potential to be applied for inactivation of SARS-CoV-2 [73]. Surface coatings can be made in many ways according to some strategies illustrated in Fig. 3.

Vreuls et al. [74] created antibacterial coatings on the stainless steel surface through the covalent graft of antibacterial peptides in an intermediate organic-polymeric layer deposited by bright radio frequency discharge plasma. Plasma polymerization under the steel surface was carried out with allyl glycidyl ether monomer. The antimicrobial peptides were covalently bonded to the surface of the polymerized steel. Covalent bonds ensured long-lasting antimicrobial functionality and were unaffected by treatments with non-ionic detergents. It was also confirmed that the peptides' antimicrobial properties remained unchanged after covalent fixation [74].

Héquet et al. [75] functionalized the stainless steel surface by covalently bonding antibacterial peptides, magainin I and nisin. Functionalization took place in three stages: (1) First, the steel surface was initially modified with chitosan to obtain $\mathrm{NH}_{2}$-rich surfaces. The chitosan physisorption occurred by immersion or deposition. In both cases, the interaction occurred between surface $\mathrm{OH}^{-}$groups and positively charged amine groups (electrostatic interactions), (2) After modifying the surface with chitosan, a crosslinking agent (glutaraldehyde) was deposited on the surface for $2 \mathrm{~h}$, then washed with water and dried with dry $\mathrm{N}_{2}$; (3) Finally, nisin and magainin were deposited on the crosslinked surface for $3 \mathrm{~h}$, and again were washed with water and dried with dry $\mathrm{N}_{2}$. The fact that chitosan has many active functional groups made it possible to graft bioactive compounds, generating functionalized surfaces with excellent antimicrobial and non-cytotoxic activity [75].

Another approach was taken by the Castro-Myoraga et al. [76] which poly (3-hydroxybutyrate-co-3-hydroxyvalerate) (PHBV) films were prepared by depositing an electrospun PHBV 18/AgNP coating on compression-molded PHBV3 films. The method consisted of preparing PHVB3 films by compression in a hot plate hydraulic press, then PHBV18 nanofibers incorporated with AgNPs were deposited in the PHVB3 film and heat-treated in a hot press, resulting in uniform and smooth films. Subsequently, the resulting films were treated at $100 \%$ relative humidity and $37^{\circ} \mathrm{C}$ for $24 \mathrm{~h}$, which prevented feline calicivirus activity and reduced murine norovirus activity by $0.86 \mathrm{log}$. The PHBV 18 polymer matrix also stabilized and reduced the aggregation of the nanoparticles [76]. 
Fig. 3 Illustrative scheme of antimicrobial coatings for various applications. Adapted with permission from Ref. [69]. Copyright 2020, ACS Publications

\section{Contact Contamination}

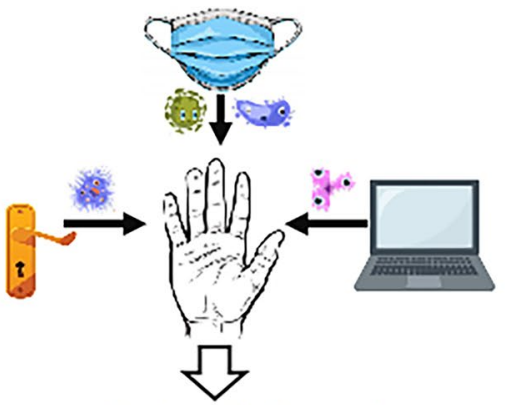

Antimicrobial Coating

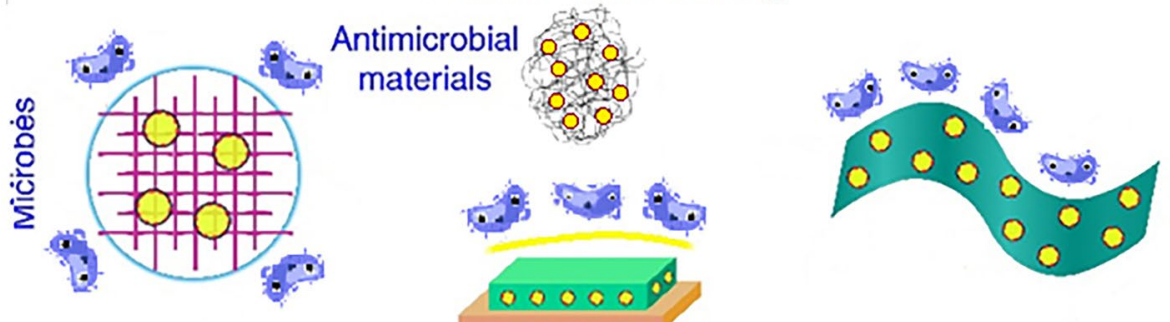

Antimicrobial textiles Antimicrobial paint Antimicrobial food packaging

Antimicrobial drug

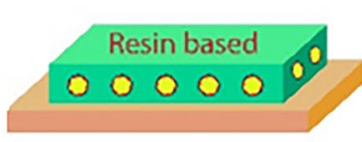

Antifouling coating

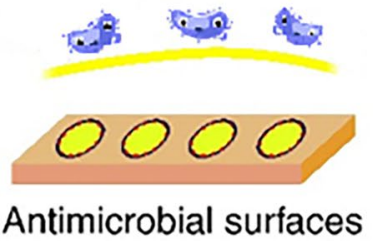

Hwang et al. [77] incorporated crystal violet (CV) into acrylic latex to produce white light-activated antimicrobial paint used to coat polyurethane samples. The results showed little leaching of CV molecules up to $100 \mathrm{~h}$ when the samples coated with $\mathrm{CV}$ paint were tested in the state immersed in phosphate-buffered saline. After $100 \mathrm{~h}$, no additional leaching was detected. Also, it has been reported that the activity of $\mathrm{CV}$ was well retained, even after mixed with acrylic latex [77].

Odeberg et al. [78] developed an antibacterial surface coating based on a cysteine ligand covalently coupled with a spacer to a carboxylic structure layer on a silicon surface grafted with acrylic acid. The coating was applied to a commercially available nasal pin. The antibacterial effect was evaluated in vitro and in vivo in a technology-based on active non-releasing compounds. The new material presented strong antibacterial activity against gram-negative and gram-positive bacteria. It did not cause environmental damage or generated accumulation in the body, as is the case with many metallic nanoparticles [78].

Ma et al. [79] produced biodegradable composite filters using the in situ deposition method to isolate pollutants and inactivate bacteria. The authors combined zeolitic-8 imidazolate/cellulose fiber structures (ZIF-8/CF), Cu-BTC metal-organic structure/ cellulose (MOF-199/CF), and metal-organic structures based on $\mathrm{Ag} /$ cellulose fiber (Ag-MOFs/CF) through simple in situ generations for the manufacture of biodegradable filters. The results demonstrated good antibacterial activity against $E$. coli due to the release of $\mathrm{Ag}^{+}$ions, significant filtration performance and antibacterial activity, and good biodegradability [79].

Kharaghani et al. [80] synthesized, using the in situ method, washable nanofibrous polyacrylonitrile (PAN) membranes with highly dispersed AgNPs, making an antibacterial mask to prevent the bidirectional bacteria effect on the environment. The method consisted of electrospinning a PAN solution and stabilizing the membrane formed by heating to $250{ }^{\circ} \mathrm{C}$ in an air atmosphere. Subsequently, the membrane was immersed in an $\mathrm{AgNO}_{3}$ solution, followed by immersion in an alkaline solution. To prepare different amounts of AgNPs, the cycle was repeated three times. Despite its lower antibacterial properties than cycles two and three, one AgNPs loading cycle's capacity was sufficient to prepare a washable antibacterial mask since the AgNP release profile for these membranes controlled the release rate for $120 \mathrm{~h}$ [80].

Liu et al. [81] grafted microcapsules of chitosan-gelatin onto cotton fabrics to assess the antibacterial effect. The 
microcapsules were placed on cotton fabrics using 2D resin (dimethylol dihydroxy ethylene urea, DMDHEU) as the crosslinking reagent. The authors reported that the antibacterial tissue rate for Staphylococcus aureus and Escherichia coli was around $65 \%$, even after being washed 25 times [81].

The inclusion of quaternary ammonium compounds (QACs) in polymers can also represent a promising strategy for preparing antimicrobial materials. Many of these compounds have low toxicity, biocompatibility, and environmental stability $[6,82]$. Literature reports show that the biocidal activity of QACs is related to the length of the R (alkyl) chain,the greater this length, the greater the hydrophobicity that makes the compound compatible with the hydrophobic lipid bilayer of the microorganism's cytoplasmic membrane. For bacteria such as E. coli and $S$. aureus, the length of the alkyl part between $\mathrm{C} 8$ and $\mathrm{C} 12$ is the most effective and, therefore, already consolidated, according to many works [83-85]. However, it still needs to be better studied in the fungi and viruses, for example. There will be a size of the alkyl group for each different microorganism that will be effective, resulting in varied molecular masses of the QACs used [8]. According to data from List $\mathrm{N}$ of the US Environmental Protection Agency (EPA), of the 430 disinfectants for use against SARS-CoV-2, 216 contain QACs as an active ingredient. Among the 18 virucidal products for surface disinfection on the Association for Applied Hygiene list in Germany, three contain QACs [86, 87]. The inclusion of these compounds in polymers can bring important results for preparing antimicrobial materials.

Druvari et al. [88] prepared biocidal coatings by mixing and crosslinking. Quaternized ammonium copolymers were studied according to the proportion of reactive groups and the type of biocidal groups. Two copolymers, poly(4vinyl benzyl chloride-co-acrylic acid) and poly(4-styrene sulfonate-co-glycidyl methacrylate), were synthesized by free-radical copolymerization and later modified, resulting in units of 4-vinyl benzyl dimethyl hexadecyl ammonium chloride and hexadecyltrimethylammonium 4-styrene sulfonate. The results showed that the curing temperature, the content of complementary reactive groups, and the type of antimicrobial species controlled the release levels and the nature of the releasable species. The crosslinking reaction involving the carboxylic and epoxy groups ensured the stabilization of the coatings [88].

Another promising alternative in combating the proliferation of microorganisms on surfaces is the superhydrophobic surfaces. They are easy to clean with the effect of autocleaning. An important feature is that these surfaces have a contact angle greater than $150^{\circ}$, related to the wetting property and consequently to the complete and simple removal of dirt and/or microbial adhesion on the surface [69]. Chemical modifications provide the surface protection feature in superhydrophobic nanocomposites. The flexibility and resistance/ durability of the surfaces according to the polymeric material. The combination of hydrophobic particles (nano) or biocidal properties also protect the surface [89].

Meguid et al. [89] reported the potential of using superhydrophobic surfaces to combat the transmission and spread of fomites infected by the virus responsible for the COVID19 pandemic. The authors developed a flexible superhydrophobic surface by dispersion hydrophobic nanoparticles in a flexible polymeric matrix (silicone), according to previous work [90]. The virus was eliminated using antiviral and antibacterial copper nanoparticles. Nanocomposites repelled contaminated drops and provided protection for surfaces used in public and health facilities, which allows the application of this new material on coating surfaces or mass synthesis in superhydrophobic monoliths. The superhydrophobic nanocomposite's mechanical properties could be varied using different polymeric materials (silicone or epoxy) to suit different substrates and operating conditions [89].

Natural polymers can represent an essential strategy for surface coatings. They are biodegradable, offer little or no toxicity to cells, and are unlikely to cause allergenic reactions. Some of these polymers are shown in Table 1 and have already been evaluated against viral strains. The biocidal activity of these polymers is correlated with their active functional groups. Chitosan is one of the most explored natural polymers for this application type due to its amino groups' protonation with high antimicrobial activity and low toxicity. He et al. [94] modified chitosan with amino groups to obtain chitosan derivatives of 6-amine-6-deoxidation (N-phthaloyl chitosan, 6-deoxy-6- bromo-N-phthaloyl chitosan, 6-aminoethylamino-6-deoxy-N-phthaloyl chitosan and, 6-aminoethylamino-6-deoxy chitosan), in order to improve their medical activity, increasing the amount of amino group and the exposure of the reaction site. The results showed that the modification significantly increased antiviral activity for the Newcastle disease virus. The RTPCR experiments indicated that 6-deoxy-6-bromo-N-phthaloyl chitosan activated the immune system and inhibited the transcription of the virus.

The main products developed based on synthetic or natural polymeric matrices for the direct combat of the Sars$\mathrm{CoV}-2$ virus, are individual protection equipment, focusing on facial masks. Bulus et al. [106] developed electrospun poly (lactic acid) membranes and reinforced them with activated carbon. The results presented a filtration efficiency $>98 \%$, indicating that this composite material has ideal properties for the production of protective equipment, such as the N95 mask layer. Singh et al. [107] proposed the synthesis of nanoporous membranes comprising carbon dots and poly(vinylidene fluoride). They demonstrated their potential use for self-sterilizing recyclable face masks. The membranes showed effective blocking of nanoparticles and necessary hydrophobicity to prevent the accumulation of 
Table 1 Natural polymers applied in the treatment of viral diseases

\begin{tabular}{|c|c|c|c|}
\hline Natural Polymer & Virus & Active group & Ref \\
\hline Chitosan & $\begin{array}{l}\text { Hepatitis B virus (HBV), Newcastle } \\
\text { disease virus receptors, herpes virus } \\
\text { (HSV), and hepatitis C virus (HCV) }\end{array}$ & Amino group and hydroxyl group & [13], [50], [91-94] \\
\hline Cellulose & HIV & Hydroxyl group & [95-98] \\
\hline Alginate & $\begin{array}{l}\text { Murine norovirus (MNV) and hepati- } \\
\text { tis A virus (HAV) since }\end{array}$ & Hydroxyl group & [99] \\
\hline Acacia gum & Monkeypox virus (MPV) & Hydroxyl group and carboxylic group & {$[15]$} \\
\hline $\begin{array}{l}\text { SP-303 } \\
\text { (polyphenolic polymer derived } \\
\text { from an Euphorbiaceae } \\
\text { shrub) }\end{array}$ & $\begin{array}{l}\text { Respiratory syncytial virus (RSV) and } \\
\text { parainfluenza virus type } 3 \text { (PIV3) }\end{array}$ & Hydroxyl group & {$[100]$} \\
\hline Hyaluronic Acid & $\mathrm{HCV}$ & $\begin{array}{l}\text { Carboxylic acid group (in } \\
\text { glucuronic acid), hydroxyl group, and } \\
\text { N-acetyl group } \\
\text { (following deamidation) }\end{array}$ & [101] \\
\hline Lignin & HSV and HIV & $\begin{array}{l}\text { Hydroxyl, methoxyl, carbonyl, and } \\
\text { carboxylic groups }\end{array}$ & [102-105] \\
\hline
\end{tabular}

moisture. The sterilization stage was performed by exposing the membranes for a short period to sunlight. The embedded $\mathrm{C}$ points absorbed visible light efficiently, giving rise to high temperatures through heat dissipation.

\section{Surface (bio)functionalization characterization techniques}

The characterization of a new material depends on how it was designed, which components are part of its structure, and mainly what is desired to be observed through this characterization. The progress made by surface functionalizations has taken place due to nanotechnology's revolution in recent years and the advance in characterization techniques involving mainly nanostructures.

The validation of surface biofunctionalization can be performed by characterization techniques such as UV-Vis spectrophotometry, circular dichroism, dynamic light scattering (DLS) and gel electrophoresis (GE), X-ray diffraction (XRD), spectroscopy Fourier transform infrared (FTIR), nuclear magnetic resonance (NMR), scanning electron microscopy (SEM), transmission electron microscopy (TEM), atomic force microscopy (AFM), and contact angle [108, 109].

\section{UV-Vis spectrophotometry}

UV-Vis absorption spectroscopy is a standard tool for nanostructures characterization [108]. The technique consists of measuring the reflected light intensity of a sample and compares it with the reflected light intensity of reference material. Nanoparticles present optical properties sensitive to size, shape, concentration, agglomeration status, and refractive index close to the surface, making UV-Vis spectroscopy an important tool for identifying, characterizing, and evaluating the stability of colloidal solutions [109]. Some well-established wavelengths can be cited. For example, the absorbance at 350-400 nm wavelength can be used to measure the concentration of Au colloid, aptamers based on oligonucleotides and antibodies based on proteins showed peaks absorption rates around 260-280 nm, and AgNPs have already shown an absorbance of 370-450 nm [108, 109].

\section{Circular dichroism}

Circular dichroism spectroscopy is used to assess the dichroic behavior of materials that they absorb to different lengths depending on the polarization of the incident beam. When the absorption of circularly polarized light in one direction (right) is different from the absorption of circularly polarized light in the opposite (left) direction, the material is said to exhibit circular dichroism. Any conformational changes in the structure of macromolecules can be evaluated using this technique. Although the UV-Vis absorption spectroscopy method remains one of the most robust techniques for characterizing macromolecules, the high extinction coefficient of nanomaterials in the UV spectrum is still a challenge [108].

\section{Dynamic light scattering (DLS) and zeta potential}

The DLS technique explores the Brownian motion of particles trapped in a solution or suspension to give rise to the sample size distribution, given by the particle's Stokes radius. The analysis can provide hydrodynamic rays, sample 
size distribution, and concentration. The zeta potential of a sample is an indicator of the stability of colloidal dispersions. Particles with a high positive or negative charge tend to repel, forming stable colloidal solutions that present small agglomeration tendencies. These measures are directly related to the $\mathrm{pH}$ values and supply us with the particles' surface charges [108, 109].

\section{Gel electrophoresis (GE)}

GE is one of the most crucial characterization techniques for biochemistry and molecular biology. It separates DNA, RNA, and other proteins, according to size and charge [108]. The technique consists of passing a current through a gel containing the molecules of interest. The molecules move at different speeds and directions through the gel, according to their size and charge, allowing them to differentiate from each other.

The speed of the biomolecules within the matrix is governed mainly by the macromolecules' specific electrophoretic mobility of the macromolecules and the applied voltage. Careful optimization of gel electrophoresis parameters can provide high resolution for differentiating DNA samples with some differences in nucleotide size and the ability to indicate whether more than one protein is involved in a complex binding sequence [108].

\section{X-Ray diffraction (XRD)}

XRD provides information on the crystalline structure, phase nature, network parameters, and crystalline grain size. An advantage of this technique is that it can provide average volume values statistically representative using the powder of colloidal solutions. The position and intensity of the peaks with the reference standards present in the International Diffraction Data Center database determine the particle composition. On the other hand, this is not a technique used for amorphous materials and particles with a size below $3 \mathrm{~nm}[109,110]$.

\section{Fourier transform infrared dpectroscopy (FTIR)}

The surface functionalization of a nanomaterial can be monitored with the aid of the FTIR technique. A biologically or chemically modified probe can be studied by the technique. A spectrum in the middle infrared region $\left(4000-400 \mathrm{~cm}^{-1}\right)$ provides information about the nature and strength of various bonds and functional groups [110]. This method depends on IV energy being absorbed by quantum energy levels associated with atomic vibrations or rotations. A registered spectrum provides the bands' position concerning the strength and nature of specific functional groups and bonds, resulting in information about molecular structures and their interactions [109]. These characteristics make the characterization technique one of the most important for studying nanoparticles' structure and interactions.

\section{Nuclear magnetic resonance (NMR)}

NMR is a spectroscopic technique used in the quantitative and structural determination of materials. Acoording to the applied field, nuclei aligned absorb energy and change the spin's orientation. This phenomenon is known as nuclear magnetic resonance. Energy absorption is a quantized process, and its value must correspond to the energy difference between the two states involved. The technique can study several nuclei, but the most commonly available are hydrogen and carbon. For the characterization of metallic nanoparticles, the technique can probe the ligand that surrounds the metal nucleus and to probe the intracellular metal atoms, for example [109].

\section{Scanning electron microscopy (SEM)}

SEM is a helpful technique for obtaining compositional, topographic, and morphological information about any solid material. The technique consists of using a focused electron beam produced at the electron source at the microscope' top. The electromagnetic lenses through the column of the microscope condition the electron beam to follow a vertical path. The microscope column focuses and directs the beam to reach the sample. Electrons and photons' emission occurs through the interaction between the beam and the material, as the electrons penetrate the surface. The appropriate detector collects the emitted particles and provides information about the surface, allowing the image's generation [111, 112].

\section{Transmission electron microscopy (TEM)}

TEM explores the interaction between an electron beam of uniform current density and a thin sample. The electrons' interaction with the sample causes electrons transmitted or scattered (elastically or inelastically). The information acquired forms the image. The interaction's magnitude depends on several factors, such as size, sample density, and elemental composition. It is an interesting technique to assess the sample's homogeneity and nanoparticles' shape and size [109].

\section{Atomic force microscopy (AFM)}

AFM is used for direct 3D visualization, texture, morphology, and surface roughness. The analysis operates through an oscillating cantilever scanned over the material under study to measure the electrostatic interactions between the tip and 
the surface. According to the degree of proximity between the probe and the sample, the AFM scanning works in three modes: contact mode, non-contact, and touch (known as an intermediate or oscillating mode). This technique can provide information about the material's biocidal properties, such as the mechanism of action of the materials when in contact with microorganisms $[111,112]$.

\section{Contact angle}

The contact angle measurement determines the surface wettability, and its value represents the wettability. The contact angle values must be between $0^{\circ}$ and $180^{\circ}$. To the contact angle less than $90^{\circ}$, the surface is classified as hydrophilic. To the wetting angle greater than $90^{\circ}$, the surface is called hydrophobic. To the contact angle approaches $180^{\circ}$, the surface is considered superhydrophobic [112].

This analysis depends on the chemistry and topography of the surface. It can provide the free surface energy of solids. One way to measure the contact angle is using a goniometer. A drop is placed on the solid surface by a syringe operated manually or automatically. Then, the image of the drop on the surface is enlarged and captured by the camera. Finally, the incidence angle between the liquid-surface interface and the liquid-vapor interface, that is, the contact angle, is measured using software [112].

\section{Future perspectives}

Pathogens are transmitted mainly by droplets. However, contaminated surfaces are able to transport the microorganism from one person to another, as evidenced by the current COVID-19 pandemic. Starting from that point, this review discussed coating materials with biocidal action. Several strategies to minimize the transmission of these pathogens, such as modifying a substrate's surface via antiviral polymers, incorporating metal ions/oxides for surface coatings, have been discussed.

Despite the infinity of works available in the literature involving antimicrobial materials, there are still many challenges for the advancement of antimicrobial materials towards their commercialization, such as guaranteeing the stability of the post-processing material and guaranteeing longer usage cycles, being still necessary to fully balance the effectiveness, toxicity and final cost of this new material.

A trend gaining ground is self-cleaning coatings (superhydrophobic surfaces), as they can prevent the attachment of infectious microdroplets to surfaces. The development of surface coatings can be responsive to stimuli, achieving better results in combating pandemics and epidemics.

Another aspect that still requires further investigation is that current antimicrobial agents are of broad-spectrum and are used to combat different pathogens. However, these biocidal molecules' interaction with different substrates (glass, wood, paper, metal, among others) is still a gap, mainly in terms of efficacy, processing, human toxicity, and sustainability.

\section{Conclusion}

This review discussed the antiviral activity of different materials. They can act as nanocarriers in the delivery of antiviral drugs, block the entry of viruses in cells, interacting with their functional groups, encapsulate drugs for controlled drug release, among other functions. The COVID-19 pandemic has been driving the development of vaccines, medicines, and biocidal materials. Therefore, the polymeric surface modification is an essential ally in functional groups' activation, making the polymer biocidal activity with potential performance in hospital environments. Finally, we would like to encourage investment in research in developing materials with antiviral properties not only during the SARSCoV-2 pandemic. Viral diseases that may arise in the future require previous studies to help achieve promising advances.

\section{References}

1. Page K, Wilson M, Parkin IP (2009) Antimicrobial surfaces and their potential in reducing the role of the inanimate environment in the incidence of hospital-acquired infections. J Mater Chem 19:3818-3831. https://doi.org/10.1039/b818698g

2. Sun Z, Ostrikov K, (Ken) (2020) Future antiviral surfaces: Lessons from COVID-19 pandemic. Sustain Mater Technol 25:e00203. https://doi.org/10.1016/j.susmat.2020.e00203

3. Chin AWH, Chu JTS, Perera MRA et al (2020) Stability of SARS-CoV-2 in different environmental conditions. The Lancet Microbe 1:e10. https://doi.org/10.1016/S2666-5247(20)30003-3

4. Lu G, Wu D, Fu R (2007) Studies on the synthesis and antibacterial activities of polymeric quaternary ammonium salts from dimethylaminoethyl methacrylate. React Funct Polym 67:355366. https://doi.org/10.1016/j.reactfunctpolym.2007.01.008

5. Hora PI, Pati SG, McNamara PJ, Arnold WA (2020) Increased use of quaternary ammonium compounds during the SARSCoV-2 pandemic and beyond: Consideration of environmental implications. Environ Sci Technol Lett 7:622-631. https://doi. org/10.1021/acs.estlett.0c00437

6. Ribeiro FOS, de Araújo GS, Mendes MGA et al (2020) Structural characterization, antifungal and cytotoxic profiles of quaternized heteropolysaccharide from Anadenanthera colubrina. Int J Biol Macromol 165:279-290. https://doi.org/10.1016/j.ijbiomac.2020. 09.087

7. Kenawy E-R, Worley SD, Broughton R (2007) The chemistry and applications of antimicrobial polymers: A state-of-the-art review. Biomacromol 8:1359-1384

8. Tavakolian M, Jafari SM, van de Ven TGM (2020) A review on surface-functionalized cellulosic nanostructures as biocompatible antibacterial materials. Nano-Micro Lett 12:73. https://doi. org/10.1007/s40820-020-0408-4 
9. von Itzstein M (2007) The war against influenza: Discovery and development of sialidase inhibitors. Nat Rev Drug Discov 6:967-974. https://doi.org/10.1038/nrd2400

10. Galdiero S, Falanga A, Vitiello $M$ et al (2011) Silver nanoparticles as potential antiviral agents. Molecules 16:8894-8918. https://doi.org/10.3390/molecules16108894

11. El-Sheekh MM, Shabaan MT, Hassan L, Morsi HH (2020) Antiviral activity of algae biosynthesized silver and gold nanoparticles against Herps Simplex (HSV-1) virus in vitro using cell-line culture technique. Int J Environ Health Res 1-12. https://doi.org/10.1080/09603123.2020.1789946

12. Sharma V, Kaushik S, Pandit P et al (2019) Green synthesis of silver nanoparticles from medicinal plants and evaluation of their antiviral potential against chikungunya virus. Appl Microbiol Biotechnol 103:881-891. https://doi.org/10.1007/ s00253-018-9488-1

13. Loutfy SA, Elberry MH, Farroh KY et al (2020) Antiviral activity of chitosan nanoparticles encapsulating curcumin against hepatitis $\mathrm{C}$ virus genotype $4 \mathrm{a}$ in human hepatoma cell lines. Int J Nanomedicine 15:2699-2715. https://doi.org/10. 2147/IJN.S241702

14. Du T, Lu J, Liu L et al (2018) Antiviral activity of graphene oxide-silver nanocomposites by preventing viral entry and activation of the antiviral innate immune response. ACS Appl Bio Mater 1:1286-1293. https://doi.org/10.1021/acsabm.8b00154

15. Rogers JV, Parkinson CV, Choi YW et al (2008) A preliminary assessment of silver nanoparticle inhibition of monkeypox virus plaque formation. Nanoscale Res Lett 3:129-133. https://doi. org/10.1007/s11671-008-9128-2

16. Liang L, Ahamed A, Ge L et al (2020) Advances in antiviral material development. Chempluschem 85:2105-2128. https:// doi.org/10.1002/cplu.202000460

17. Pedroso-Santana S, Lamazares Arcia E, Fleitas-Salazar N et al (2020) Polymeric nanoencapsulation of alpha interferon increases drug bioavailability and induces a sustained antiviral response in vivo. Mater Sci Eng C 116:111260. https://doi.org/ 10.1016/j.msec.2020.111260

18. Sahu DK, Pradhan D, Naik PK et al (2020) Smart polymeric eye gear: A possible preventive measure against ocular transmission of COVID-19. Med Hypotheses 144:110288. https://doi.org/10. 1016/j.mehy.2020.110288

19. Reina G, Peng S, Jacquemin L et al (2020) Hard nanomaterials in time of viral pandemics. ACS Nano 14:9364-9388. https:// doi.org/10.1021/acsnano.0c04117

20. Sharma VK, Siskova KM, Zboril R, Gardea-Torresdey JL (2014) Organic-coated silver nanoparticles in biological and environmental conditions: Fate, stability and toxicity. Adv Colloid Interface Sci 204:15-34. https://doi.org/10.1016/j.cis.2013.12.002

21. Lin Z, Li Y, Guo M et al (2017) The inhibition of H1N1 influenza virus-induced apoptosis by silver nanoparticles functionalized with zanamivir. RSC Adv 7:742-750. https://doi.org/10.1039/ C6RA25010F

22. Sofy AR, Hmed AA, Abd El Haliem NF et al (2019) Polyphosphoniumoligochitosans decorated with nanosilver as new prospective inhibitors for common human enteric viruses. Carbohydr Polym 226:115261. https://doi.org/10.1016/j.carbpol.2019.115261

23. Li Y, Lin Z, Xu T et al (2017) Delivery of VP1 siRNA to inhibit the EV71 virus using functionalized silver nanoparticles through ROS-mediated signaling pathways. RSC Adv 7:1453-1463. https://doi.org/10.1039/C6RA26472G

24. Thompson CI (2004) Changes in in vitro susceptibility of influenza A H3N2 viruses to a neuraminidase inhibitor drug during evolution in the human host. J Antimicrob Chemother 53:759-765. https:// doi.org/10.1093/jac/dkh155

25. Haroun AA, Amin HA, Abd El-Alim SH (2018) Immobilization and in vitro evaluation of soyasapogenol $\mathrm{B}$ onto functionalized multi-walled carbon nanotubes. IRBM 39:35-42. https://doi.org/ 10.1016/j.irbm.2017.12.003

26. Sarkisyan ZM (2020) Biologically active fullerene derivatives. Russ J Gen Chem 90:1853-1862. https://doi.org/10.1134/ S1070363220100072

27. Yang XX, Li CM, Li YF et al (2017) Synergistic antiviral effect of curcumin functionalized graphene oxide against respiratory syncytial virus infection. Nanoscale 9:16086-16092. https://doi. org/10.1039/C7NR06520E

28. Barras A, Pagneux Q, Sane F et al (2016) High efficiency of functional carbon nanodots as entry inhibitors of herpes simplex virus type 1 . ACS Appl Mater Interfaces 8:9004-9013. https://doi.org/10.1021/ acsami.6b01681

29. Mazzaglia A, Scala A, Sortino G et al (2018) Intracellular trafficking and therapeutic outcome of multiwalled carbon nanotubes modified with cyclodextrins and polyethylenimine. Colloids Surfaces B Biointerfaces 163:55-63. https://doi.org/10.1016/j.colsurfb.2017.12.028

30. Sijbesma R, Srdanov G, Wudl F et al (1993) Synthesis of a fullerene derivative for the inhibition of HIV enzymes. J Am Chem Soc 115:6510-6512. https://doi.org/10.1021/ja00068a006

31. Yasuno T, Ohe T, Kataoka $\mathrm{H}$ et al (2021) Fullerene derivatives as dual inhibitors of HIV-1 reverse transcriptase and protease. Bioorganic Med Chem Lett 31:127675. https://doi.org/10.1016/j. bmcl.2020.127675

32. Zhou J, Krishnan N, Jiang Y et al (2021) Nanotechnology for virus treatment. Nano Today 36:101031. https://doi.org/10. 1016/j.nantod.2020.101031

33. Requião RD, Carneiro RL, Moreira MH et al (2020) Viruses with different genome types adopt a similar strategy to pack nucleic acids based on positively charged protein domains. Sci Rep 10:5470. https://doi.org/10.1038/s41598-020-62328-w

34. Sametband M, Kalt I, Gedanken A, Sarid R (2014) Herpes simplex virus type-1 attachment inhibition by functionalized graphene oxide. ACS Appl Mater Interfaces 6:1228-1235. https://doi.org/10.1021/ am405040z

35. Lim SY, Shen W, Gao Z (2015) Carbon quantum dots and their applications. Chem Soc Rev 44:362-381. https://doi.org/10. 1039/C4CS00269E

36. Łoczechin A, Séron K, Barras A et al (2019) Functional carbon quantum dots as medical countermeasures to human coronavirus. ACS Appl Mater Interfaces 11:42964-42974. https://doi.org/10. 1021/acsami.9b15032

37. Lin LC, Huang C, Yao B et al (2019) Viromimetic STING agonist-loaded hollow polymeric nanoparticles for safe and effective vaccination against middle east respiratory syndrome coronavirus. Adv Funct Mater 29:1807616. https://doi.org/10.1002/adfm. 201807616

38. Carraher CE, Roner MR (2014) Organotin polymers as anticancer and antiviral agents. J Organomet Chem 751:67-82. https://doi. org/10.1016/j.jorganchem.2013.05.033

39. Chen L, Liang J (2020) An overview of functional nanoparticles as novel emerging antiviral therapeutic agents. Mater Sci Eng C 112:110924. https://doi.org/10.1016/j.msec.2020.110924

40. Adki KM, Kulkarni YA (2020) Chemistry, pharmacokinetics, pharmacology and recent novel drug delivery systems of paeonol. Life Sci 250:117544. https://doi.org/10.1016/j.lfs.2020. 117544

41. Chowdhury AH, Debnath R, Islam SM, Saha T (2019) Impact of nanoparticle shape, size, and properties of silver nanocomposites and their applications. Sustainable polymer composites and nanocomposites. Springer International Publishing, Cham, pp 1067-1091. https://doi. org/10.1007/978-3-030-05399-4_37

42. Park S, Ko Y-S, Lee SJ et al (2018) Inactivation of influenza A virus via exposure to silver nanoparticle-decorated silica hybrid composites. Environ Sci Pollut Res 25:27021-27030. https://doi. org/10.1007/s11356-018-2620-z 
43. Chen Y-N, Hsueh Y-H, Hsieh C-T et al (2016) Antiviral activity of graphene-silver nanocomposites against non-enveloped and enveloped viruses. Int J Environ Res Public Health 13:430. https://doi. org/10.3390/ijerph13040430

44. Repkova M, Levina A, Chelobanov B et al (2017) Efficient inhibition of influenza A viral replication in cells by deoxyribozymes delivered by nanocomposites. Int J Antimicrob Agents 49:703708. https://doi.org/10.1016/j.ijantimicag.2017.01.026

45. de Castro KC, Mei LHI, Carvalho FC, Campos MGN (2019) Charge tunable chitosan/PLA microspheres for potential biomedical application. Mater Res Express 6:125403. https://doi. org/10.1088/2053-1591/ab547a

46. de Castro KC, van de Graaf GMM, Marques RFC, Campos MGN (2019) Chitosan and collagen composite for potential application as bone substitute. Res Biomed Eng 35.https://doi.org/10.1007/ s42600-019-00002-5

47. Loh XJ, Wu Y-L (2015) Cationic star copolymers based on $\beta$-cyclodextrins for efficient gene delivery to mouse embryonic stem cell colonies. Chem Commun 51:10815-10818. https://doi. org/10.1039/C5CC03686K

48. Loh XJ, Ong SJ, Tung YT, Choo HT (2013) Co-delivery of drug and DNA from cationic dual-responsive micelles derived from poly(DMAEMA-co-PPGMA). Mater Sci Eng C 33:4545-4550. https://doi.org/10.1016/j.msec.2013.07.011

49. Kozhikhova KV, Ivantsova MN, Tokareva MI et al (2018) Preparation of chitosan-coated liposomes as a novel carrier system for the antiviral drug Triazavirin. Pharm Dev Technol 23:334-342. https://doi.org/10.1080/10837450.2016.1242624

50. Donalisio M, Leone F, Civra A et al (2018) Acyclovir-loaded chitosan nanospheres from nano-emulsion templating for the topical treatment of herpesviruses infections. Pharmaceutics 10:46. https://doi.org/10.3390/pharmaceutics10020046

51. Garrido PF, Calvelo M, Blanco-González A et al (2020) The Lord of the NanoRings: Cyclodextrins and the battle against SARS-CoV-2. Int J Pharm 588:119689. https://doi.org/10.1016/j. ijpharm.2020.119689

52. Padmanabhan Srivatsan (2020) Potential dual therapeutic approach against SARS-CoV-2/COVID-19 with nitazoxanide and hydroxychloroquine. Preprint. https://doi.org/10.13140/ RG.2.2.28124.74882

53. Gao J, Tian Z, Yang X (2020) Breakthrough: Chloroquine phosphate has shown apparent efficacy in treatment of COVID-19 associated pneumonia in clinical studies. Biosci Trends 14:7273. https://doi.org/10.5582/bst.2020.01047

54. Németh K, Tárkányi G, Varga E et al (2011) Enantiomeric separation of antimalarial drugs by capillary electrophoresis using neutral and negatively charged cyclodextrins. J Pharm Biomed Anal 54:475-481. https://doi.org/10.1016/j.jpba.2010.09.020

55. Geleris J, Sun Y, Platt J et al (2020) Observational Study of Hydroxychloroquine in Hospitalized Patients with Covid19. N Engl J Med 382:2411-2418. https://doi.org/10.1056/ NEJMoa2012410

56. Skalickova S, Heger Z, Krejcova L et al (2015) Perspective of use of antiviral peptides against influenza virus. Viruses 7:54285442. https://doi.org/10.3390/v7102883

57. Brauer F, Schmidt K, Zahn RC et al (2013) A rationally engineered anti-HIV peptide fusion inhibitor with greatly reduced immunogenicity. Antimicrob Agents Chemother 57:679-688. https://doi.org/10.1128/AAC.01152-12

58. Vagner J, Qu H, Hruby VJ (2008) Peptidomimetics, a synthetic tool of drug discovery. Curr Opin Chem Biol 12:292-296. https://doi.org/10.1016/j.cbpa.2008.03.009

59. Schütz D, Ruiz-Blanco YB, Münch J et al (2020) Peptide and peptide-based inhibitors of SARS-CoV-2 entry. Adv Drug Deliv Rev 167:47-65. https://doi.org/10.1016/j.addr.2020.11. 007
60. Walls AC, Park Y, Tortorici MA et al (2020) Structure, Function, and Antigenicity of the SARS-CoV-2 Spike Glycoprotein. Cell 181:281-292.e6. https://doi.org/10.1016/j.cell.2020.02.058

61. Shirato K, Kawase M, Matsuyama S (2018) Wild-type human coronaviruses prefer cell-surface TMPRSS2 to endosomal cathepsins for cell entry. Virology 517:9-15. https://doi.org/10. 1016/j.virol.2017.11.012

62. Bazaka K, Jacob MV, Chrzanowski W, Ostrikov K (2015) Antibacterial surfaces: natural agents, mechanisms of action, and plasma surface modification. RSC Adv 5:48739-48759. https:// doi.org/10.1039/C4RA17244B

63. Bazaka K, Jacob MV, Crawford RJ, Ivanova EP (2012) Efficient surface modification of biomaterial to prevent biofilm formation and the attachment of microorganisms. Appl Microbiol Biotechnol 95:299-311. https://doi.org/10.1007/s00253-012-4144-7

64. Greenhalgh R, Dempsey-Hibbert NC, Whitehead KA (2019) Antimicrobial strategies to reduce polymer biomaterial infections and their economic implications and considerations. Int Biodeterior Biodegradation 136:1-14. https://doi.org/10.1016/j. ibiod.2018.10.005

65. Greenhalgh R, Walker JT (2017) Antimicrobial strategies for polymeric hygienic surfaces in healthcare. Int Biodeterior Biodegradation 125:214-227. https://doi.org/10.1016/j.ibiod.2017. 09.009

66. Krishnan S, Weinman CJ, Ober CK (2008) Advances in polymers for anti-biofouling surfaces. J Mater Chem 18:3405. https://doi. org/10.1039/b801491d

67. Moreno-Couranjou M, Mauchauffé R, Bonot S et al (2018) Antibiofouling and antibacterial surfaces via a multicomponent coating deposited from an up-scalable atmospheric-pressure plasmaassisted CVD process. J Mater Chem B 6:614-623. https://doi. org/10.1039/C7TB02473H

68. Francolini I, Vuotto C, Piozzi A, Donelli G (2017) Antifouling and antimicrobial biomaterials: An overview. APMIS 125:392417. https://doi.org/10.1111/apm.12675

69. Balasubramaniam B, Prateek, Ranjan S, et al (2020) Antibacterial and antiviral functional materials: Chemistry and biological activity toward tackling COVID-19-like pandemics. ACS Pharmacol Transl Sci 4:8-54. https://doi.org/10.1021/acsptsci.0c00174

70. Huang K-S, Yang C-H, Huang S-L et al (2016) Recent advances in antimicrobial polymers: A mini-review. Int J Mol Sci 17:1578. https://doi.org/10.3390/ijms17091578

71. Sedlarik V (2013) Antimicrobial modifications of polymers. In: Biodegradation - Life of Science. InTech, pp 187-204

72. Chen Y, Han Q (2011) Designing N-halamine based antibacterial surface on polymers: Fabrication, characterization, and biocidal functions. Appl Surf Sci 257:6034-6039. https://doi.org/10. 1016/j.apsusc.2011.01.115

73. Singh Siwal S, Zhang Q, Kumar Saini A, Kumar Thakur V (2020) Antimicrobial materials: New strategies to tackle various pandemics. J Renew Mater 8:1543-1563. https://doi.org/10. 32604/jrm.2020.014597

74. Vreuls C, Zocchi G, Thierry B et al (2010) Prevention of bacterial biofilms by covalent immobilization of peptides onto plasma polymer functionalized substrates. J Mater Chem 20:8092. https://doi.org/10.1039/c0jm01419b

75. Héquet A, Humblot V, Berjeaud J-M, Pradier C-M (2011) Optimized grafting of antimicrobial peptides on stainless steel surface and biofilm resistance tests. Colloids Surfaces B Biointerfaces 84:301-309. https://doi.org/10.1016/j.colsurfb. 2011.01.012

76. Castro-Mayorga JL, Randazzo W, Fabra MJ et al (2017) Antiviral properties of silver nanoparticles against norovirus surrogates and their efficacy in coated polyhydroxyalkanoates systems. LWT - Food Sci Technol 79:503-510. https://doi.org/10.1016/j. lwt.2017.01.065 
77. Hwang GB, Allan E, Parkin IP (2016) White light-activated antimicrobial paint using crystal violet. ACS Appl Mater Interfaces 8:15033-15039. https://doi.org/10.1021/acsami.5b06927

78. Odeberg J, Wirsén A, Norberg A et al (2018) A novel cysteinelinked antibacterial surface coating significantly inhibits bacterial colonization of nasal silicone prongs in a phase one pre-clinical trial. Mater Sci Eng C 93:782-789. https://doi.org/10.1016/j. msec.2018.08.040

79. Ma S, Zhang M, Nie J et al (2018) Multifunctional cellulosebased air filters with high loadings of metal-organic frameworks prepared by in situ growth method for gas adsorption and antibacterial applications. Cellulose 25:5999-6010. https://doi.org/ 10.1007/s10570-018-1982-1

80. Kharaghani D, Khan M, Shahzad A et al (2018) Preparation and in-vitro assessment of hierarchal organized antibacterial breath mask based on polyacrylonitrile/silver (PAN/AgNPs) nanofiber. Nanomaterials 8:461. https://doi.org/10.3390/nano8070461

81. Liu J, Liu C, Liu Y et al (2013) Study on the grafting of chitosangelatin microcapsules onto cotton fabrics and its antibacterial effect. Colloids Surfaces B Biointerfaces 109:103-108. https:// doi.org/10.1016/j.colsurfb.2013.03.040

82. Jiao Y, Niu L, Ma S et al (2017) Quaternary ammonium-based biomedical materials: State-of-the-art, toxicological aspects and antimicrobial resistance. Prog Polym Sci 71:53-90. https://doi. org/10.1016/j.progpolymsci.2017.03.001

83. Kwaśniewska D, Chen Y-L, Wieczorek D (2020) Biological activity of quaternary ammonium salts and their derivatives. Pathogens 9:459. https://doi.org/10.3390/pathogens9060459

84. Mathew RT, Cooney RP, Doyle CS et al (2020) Anchored quaternary ammonium salts adsorbed on polyurethane film surfaces. Prog Org Coatings 138:105343. https://doi.org/10.1016/j.porgcoat. 2019.105343

85. Rewak-Soroczyńska J, Paluch E, Siebert A et al (2019) Biological activity of glycine and alanine derivatives of quaternary ammonium salts (QASs) against micro-organisms. Lett Appl Microbiol 69:212-220. https://doi.org/10.1111/lam.13195

86. VAH List of Disinfectants (2020). https://vah-liste.mhp-verlag.de/en/. Accessed 13 Nov 2020

87. United States Environmental Protection Agency (2020) List N: Disinfectants for use against SARS-CoV-2. https://www.epa.gov/ pesticide-registration/list-n-disinfectants-use-against-sars-cov-2 . Accessed 13 Nov 2020

88. Druvari D, Koromilas N, Bekiari V et al (2017) Polymeric antimicrobial coatings based on quaternary ammonium compounds. Coatings 8:8. https://doi.org/10.3390/coatings 8010008

89. Meguid SA, Elzaabalawy A (2020) Potential of combating transmission of COVID-19 using novel self-cleaning superhydrophobic surfaces: part I-protection strategies against fomites. Int J Mech Mater Des 16:423-431. https://doi.org/10.1007/s10999-020-09513-x

90. Elzaabalawy A, Verberne P, Meguid SA (2019) Multifunctional silica-silicone nanocomposite with regenerative superhydrophobic capabilities. ACS Appl Mater Interfaces 11:42827-42837. https:// doi.org/10.1021/acsami.9b15445

91. Hong Y, Mao D, Wu R et al (2019) Hepatitis B virus S gene therapy with 10-23 DNAzyme delivered by chitosan- $\mathrm{g}$-stearic acid micelles. RSC Adv 9:15196-15204. https://doi.org/10.1039/ C9RA00330D

92. Russo E, Gaglianone N, Baldassari S et al (2014) Preparation, characterization and in vitro antiviral activity evaluation of foscarnetchitosan nanoparticles. Colloids Surfaces B Biointerfaces 118:117125. https://doi.org/10.1016/j.colsurfb.2014.03.037

93. Karthik R, Manigandan V, Saravanan R et al (2016) Structural characterization and in vitro biomedical activities of sulfated chitosan from Sepia pharaonis. Int J Biol Macromol 84:319-328. https://doi.org/10.1016/j.ijbiomac.2015.12.030
94. He X, Xing R, Liu S et al (2019) The improved antiviral activities of amino-modified chitosan derivatives on Newcastle virus. Drug Chem Toxicol 1-6. https://doi.org/10.1080/01480545. 2019.1620264

95. Neurath AR, Strick N, Li Y-Y (2002) Anti-HIV-1 activity of anionic polymers: A comparative study of candidate microbicides. BMC Infect Dis 2:27. https://doi.org/10.1186/1471-2334-2-27

96. Malonza IM, Mirembe F, Nakabiito C et al (2005) Expanded phase I safety and acceptability study of $6 \%$ cellulose sulfate vaginal gel. AIDS 19:2157-2163. https://doi.org/10.1097/01. aids.0000194797.59046.8f

97. Van Damme L, Govinden R, Mirembe FM et al (2008) Lack of effectiveness of cellulose sulfate gel for the prevention of vaginal HIV transmission. N Engl J Med 359:463-472. https://doi.org/ 10.1056/NEJMoa0707957

98. Yamamoto I, Takayama K, Honma K et al (1990) Synthesis, structure and antiviral activity of sulfates of cellulose and its branched derivatives. Carbohydr Polym 14:53-63. https://doi. org/10.1016/0144-8617(90)90006-E

99. Fabra MJ, Falcó I, Randazzo W et al (2018) Antiviral and antioxidant properties of active alginate edible films containing phenolic extracts. Food Hydrocoll 81:96-103. https://doi.org/ 10.1016/j.foodhyd.2018.02.026

100. Wyde PR, Ambrose MW, Meyerson LR, Gilbert BE (1993) The antiviral activity of SP-303, a natural polyphenolic polymer, against respiratory syncytial and parainfluenza type 3 viruses in cotton rats. Antiviral Res 20:145-154. https://doi.org/10.1016/ 0166-3542(93)90004-3

101. Lee M-Y, Yang J-A, Jung HS et al (2012) Hyaluronic acid-gold nanoparticle/interferon $\alpha$ complex for targeted treatment of hepatitis C virus infection. ACS Nano 6:9522-9531. https://doi.org/ 10.1021/nn302538y

102. Vinardell MP, Mitjans M (2017) Lignins and their derivatives with beneficial effects on human health. Int J Mol Sci 18:1219. https://doi.org/10.3390/ijms18061219

103. Thakkar JN, Tiwari V, Desai UR (2010) Nonsulfated, cinnamic acid-based lignins are potent antagonists of HSV-1 entry into cells. Biomacromol 11:1412-1416. https://doi.org/10.1021/ bm100161u

104. Lee J-B, Yamagishi C, Hayashi K, Hayashi T (2011) Antiviral and immunostimulating effects of lignin-carbohydrate-protein complexes from pimpinella anisum. Biosci Biotechnol Biochem 75:459-465. https://doi.org/10.1271/bbb. 100645

105. Gordts SC, Férir G, D'huys T et al (2015) The low-cost compound lignosulfonic acid (LA) exhibits broad-spectrum anti-HIV and antiHSV activity and has potential for microbicidal applications. PLoS ONE 10:e0131219. https://doi.org/10.1371/journal.pone.0131219

106. Buluş E, Buluş GS, Yakuphanoglu F (2021) Production of polylactic acid-activated charcoal nanofiber membranes for COVID-19 pandemic by electrospinning technique and determination of filtration efficiency. J Mater Electron Devices 4:21-26

107. Singh S, Shauloff N, Sharma CP et al (2021) Carbon dot-polymer nanoporous membrane for recyclable sunlight-sterilized facemasks. J Colloid Interface Sci 592:342-348. https://doi.org/10.1016/j.jcis. 2021.02.049

108. Yüce M, Kurt H (2017) How to make nanobiosensors: surface modification and characterisation of nanomaterials for biosensing applications. RSC Adv 7:49386-49403. https://doi.org/10.1039/ C7RA10479K

109. Mourdikoudis S, Pallares RM, Thanh NTK (2018) Characterization techniques for nanoparticles: Comparison and complementarity upon studying nanoparticle properties. Nanoscale 10:12871-12934. https://doi.org/10.1039/C8NR02278J

110. Purohit B, Vernekar PR, Shetti NP, Chandra P (2020) Biosensor nanoengineering: Design, operation, and implementation for 
biomolecular analysis. Sensors Int 1:100040. https://doi.org/10. 1016/j.sintl.2020.100040

111. Ebnesajjad S (2014) Surface and material characterization techniques. In: Surface treatment of materials for adhesive bonding. Elsevier, pp 39-75

112. Erdoğan G, Güler G, Kiliç T et al (2016) Surface characterization techniques. Surface treatments for biological, chemical, and physical applications. Wiley-VCH Verlag GmbH \& Co. KGaA, Weinheim, Germany, pp 67-114

Publisher's Note Springer Nature remains neutral with regard to jurisdictional claims in published maps and institutional affiliations. 